\title{
A OUVIDORIA COMO FERRAMENTA DE GESTÃO DO SUS NO ESTADO DO RIO GRANDE DO SUL
}

\author{
Luana Gonçalves Gehres/ SES/RS ${ }^{1}$ \\ Bruna Campos De Cesaro
}

\begin{abstract}
Resumo
A Ouvidoria do Sistema Único de Saúde (SUS) é o canal de atendimento ao cidadão para recebimento de elogios, sugestões, solicitações, reclamações, denúncias e informações do SUS, sendo um dos espaços para o exercício da cidadania, participação e controle social. Tem a finalidade de identificar áreas deficitárias, subsidiando as tomadas de decisão dos gestores para melhoria da qualidade dos serviços de saúde. O objetivo desta pesquisa foi identificar os assuntos recorrentes nos protocolos gerados na Ouvidoria do SUS do Rio Grande do Sul, a fim de gerar impacto na avaliação e planejamento em saúde. Trata-se de uma pesquisa de abordagem quantitativa realizada a partir dos dados disponíveis no sistema informatizado por meio da análise e categorização dos assuntos mais recorrentes nas manifestações dos cidadãos. No ano de 2016 se obteve o registro de 6.096 manifestações. A partir da identificação dos assuntos de maior recorrência, é possível influenciar no estabelecimento de metas e pactuações em saúde, para que as ações de planejamento reflitam efetiva e concretamente os anseios dos usuários, de modo que possa influenciar, inclusive, na elaboração do Plano Estadual de Saúde e na pactuação de indicadores e metas da saúde nos Municípios.
\end{abstract}

Palavras-chave: Defesa do paciente. Sistema Único de Saúde. Saúde Pública.

1 Ouvidora Estadual do SUS. Coordenadora da Ouvidoria do SUS no Governo do Estado do RS. Servidora Estadual na Secretaria de Saúde do RS. Especialista em Saúde da Família e Comunidade. (luana-gehres@saude.rs.gov.br) 2 Ouvidora Regional do SUS. Mestranda em Saúde Coletiva UFGRS. Especialista em Gestão de Redes de Atenção à Saúde Fiocruz. Servidora Estadual na Secretaria de Saúde do RS. (bruna-cesaro@saude.rs.gov.br) Av. Borges de Medeiros, 1501, $1^{\circ}$ andar, PoA/RS, CEP: 90119-900, Fone: (51) 3288-7952 - Site: http://www.saude. rs.gov.br/ouvidoria - E-mail: ouvidoria-sus@saude.rs.gov.br. 


\begin{abstract}
The Ombudsman's Office of the Unified Health System is the citizen's service channel for receiving compliments, suggestions, requests, complaints, denunciations and information, being one of the channels for the exercise of citizenship. Its purpose is identifying deficit areas, subsidizing managers decisions to improve quality of the health services. Through computerized system (OuvidorSUS), it is possible to have access to managerial data, with data tabulation and identification of recurring themes. The objective of this research was to identify the most common health issues in SUS of Rio Grande do Sul, in order to generate impact in health evaluation and planning. It is a quantitative approach based on the data available in the computerized system through the analysis and categorization of procedures and applicants in the manifestations of citizens. In the year 2016 was registered 6,096 protocols. From the identification of the problems of higher incidence, the data obtained can influence the establishment of goals and agreements, so that the planning actions effectively and concretely reflect the users' wishes. It is understood that this research should be used for evaluation and planning of health actions, so that it can influence, also, in the elaboration of the State Health Plan and in the evaluation of health goals in municipalities.
\end{abstract}

Keywords: Patient Advocacy. Unified Health System. Public Health. 


\section{INTRODUÇÃO}

O primeiro Ombudsman surgiu há mais de três séculos, o termo sueco significa, em português, representante do rei, cuja principal função era supervisionar os serviços dos funcionários do governo e, com o passar do tempo, ficou com a responsabilidade de defender o cidadão contra os excessos da burocracia. Posteriormente, a palavra Ombudsman passou a agregar um sentido de "defensor do cidadão" ou o termo "do povo" (SASKATCHEWAN, 2010). No Brasil, o profissional Ombudsman ficou mais conhecido como Ouvidor. Em 1983, juntamente com o processo de redemocratização, a Ouvidoria que existe nos moldes atuais começou a ser discutida, sendo instalada a primeira Ouvidoria Pública em Curitiba - Ouvidoria Municipal de Curitiba, PR. No âmbito estadual, o Estado do Paraná também foi pioneiro, sendo a primeira unidade federativa a instituí-la em 1991. Já a instituição da Ouvidoria-Geral da República ocorreu posteriormente, com a Lei Federal n 8.490, de 19 de novembro de 1992 (PEIXOTO, 2013).

A Ouvidoria Pública no cenário brasileiro cresceu em quantidade nas diferentes esferas de governo nos últimos anos, e o grande número de protocolos gerados mostra a necessidade que o cidadão brasileiro apresenta em ter uma instituição que possa, além de defender seus direitos, promovê-los para além dos já reconhecidos espaços de exercício da cidadania (ZAVERUCHA, 2008). O atual modelo de democracia representativa oferece ao cidadão o direito de voto, mas, uma vez encerrado o processo eleitoral, reserva a um pequeno grupo a responsabilidade pelo exercício do Poder Público; é nesse contexto que se abre a discussão em torno da democracia participativa, uma proposta que coexiste com o modelo representativo, a fim de complementá-lo e aperfeiçoá-lo, na medida em que abre espaço para uma participação efetiva da sociedade civil na gestão pública. Auxilia ainda na consecução do objetivo de ampliar a participação da sociedade no controle do Estado, lançando as bases de uma democracia participativa, na qual as Ouvidorias, Conselhos e demais instituições do controle social têm papel primordial a cumprir (LYRA, 2004).

\section{DESENVOLVIMENTO}

\subsection{Fundamentação Teórica}

A Ouvidoria-Geral do SUS (Sistema Único de Saúde) pertence à Secretaria de Gestão Estratégica e Participativa do governo federal, vinculada ao Ministério da Saúde e criada pelo Decreto $n^{\circ}$ 4.726, de 9 de junho de 2003. Três anos após a sua criação, foi implantado o Sistema Informatizado OuvidorSUS, interligando as diferentes Ouvidorias do SUS, para acompanhamento e resolutividade dos protocolos gerados, e hoje presente em todos estados e diversos municípios brasileiros. As Ouvidorias procuraram auxiliar o processo de construção da cidadania nas últimas décadas em nosso país, elas são órgãos cuja função principal é "ouvir" a manifestação acerca dos serviços prestados, intervindo na relação entre o usuário e a Administração Pública. O conhecimento da opinião dos usuários em relação aos serviços públicos é importante instrumento 
auxiliar para planejamento e tomada de decisões. As Ouvidorias Públicas são de cunho universalista e tentam estimular a propagação da cidadania e da gestão participativa (PINTO e LYRA, 2009).

A Participação Social no Sistema Único de Saúde (SUS) é uma diretriz constitucional descrita nas Leis n. ${ }^{\circ} 8.080 / 90$ e n. ${ }^{\circ} 8.142 / 90$, parte fundamental da constituição da saúde pública brasileira. Além das Ouvidorias, os conselhos de saúde contam com outras instituições de controle social nas políticas públicas, tais como: auditorias, Ministério Público, controladorias, Tribunais de Contas, comissões do Legislativo, entre outros, que devem ser acionados sempre que necessário (BRASIL, 2007).

O financiamento da saúde pública no país é feito de forma tripartite, ou seja, consiste no conjunto das parcelas de gastos da União, Estados e Municípios. A União formula políticas nacionais, mas a implementação é feita pelos Estados e Municípios. O município é o principal responsável pela saúde pública de sua população, tendo gestão das ações e serviços de saúde oferecidos em seu território. Já o governo estadual implementa políticas nacionais e estaduais, além de organizar o atendimento à saúde em seu território. A porta de entrada do sistema de saúde deve ser preferencialmente a atenção básica (Postos de Saúde, Unidades de Saúde da Família etc.). A partir desse primeiro atendimento, o cidadão será encaminhado para os outros serviços de maior complexidade da saúde pública (hospitais e clínicas especializadas). O sistema público de saúde funciona de forma referenciada. Isso ocorre quando o gestor local do SUS, não dispondo do serviço de que o usuário necessita, encaminha-o para outra localidade que oferece o serviço. Esse encaminhamento e a referência de atenção à saúde são pactuados entre os municípios, e por vezes com o Estado e a União, buscando o atendimento integral à saúde da população. Há competências definidas para cada um desses três gestores, consolidando um Sistema Único de Saúde, o SUS, que por sua vez articula-se em Rede de forma regionalizada da qual faz parte a Ouvidoria. Esta regionalização constitui-se como um processo de articulação entre os serviços que já existem, visando um comando unificado (BRASIL, 2006).

A Secretaria de Saúde do Rio Grande do Sul, atendendo às diretrizes preconizadas pelo SUS, utiliza a seguinte estruturação regional a fim de organizar a política de saúde no Estado e a rede de serviços do SUS: Regiões de Saúde e Coordenadorias Regionais de Saúde e Macrorregiões. Destas, as Coordenadorias Regionais de Saúde (CRS) representam as sedes administrativas regionais responsáveis pelo planejamento, acompanhamento e gerenciamento das ações e serviços de saúde em seu território (RIO GRANDE DO SUL, 2011), compostas por 19 sedes, conforme figura 1.

Em 2012 iniciou-se a implantação da Ouvidoria do SUS da Secretaria Estadual de Saúde do Rio Grande do Sul (SES/RS) por meio da designação de três Ouvidores e capacitação de servidores como pontos de interlocução em diversos setores do órgão, incluindo as Coordenadorias Regionais de Saúde (CRS) - que posteriormente tornaram-se as Ouvidorias do SUS Regionais - compondo a Rede da Ouvidoria do SUS. A regulamentação deste processo ocorreu através do Decreto Estadual n. ${ }^{\circ}$ 51.999/2014, efetivando-se a implantação das 19 (dezenove) Ouvidorias Regionais do SUS, com a designação dos seus respectivos Ouvidores Regionais. Ainda foram designados outros 03 (três) Ouvidores Internos para atuarem em departamentos da SES mais demandados. Todos esses vinculados à Ouvidoria Estadual, tendo suas competências descritas no Regimento Interno da Ouvidoria do SUS (RIO GRANDE DO SUL, 2014). 


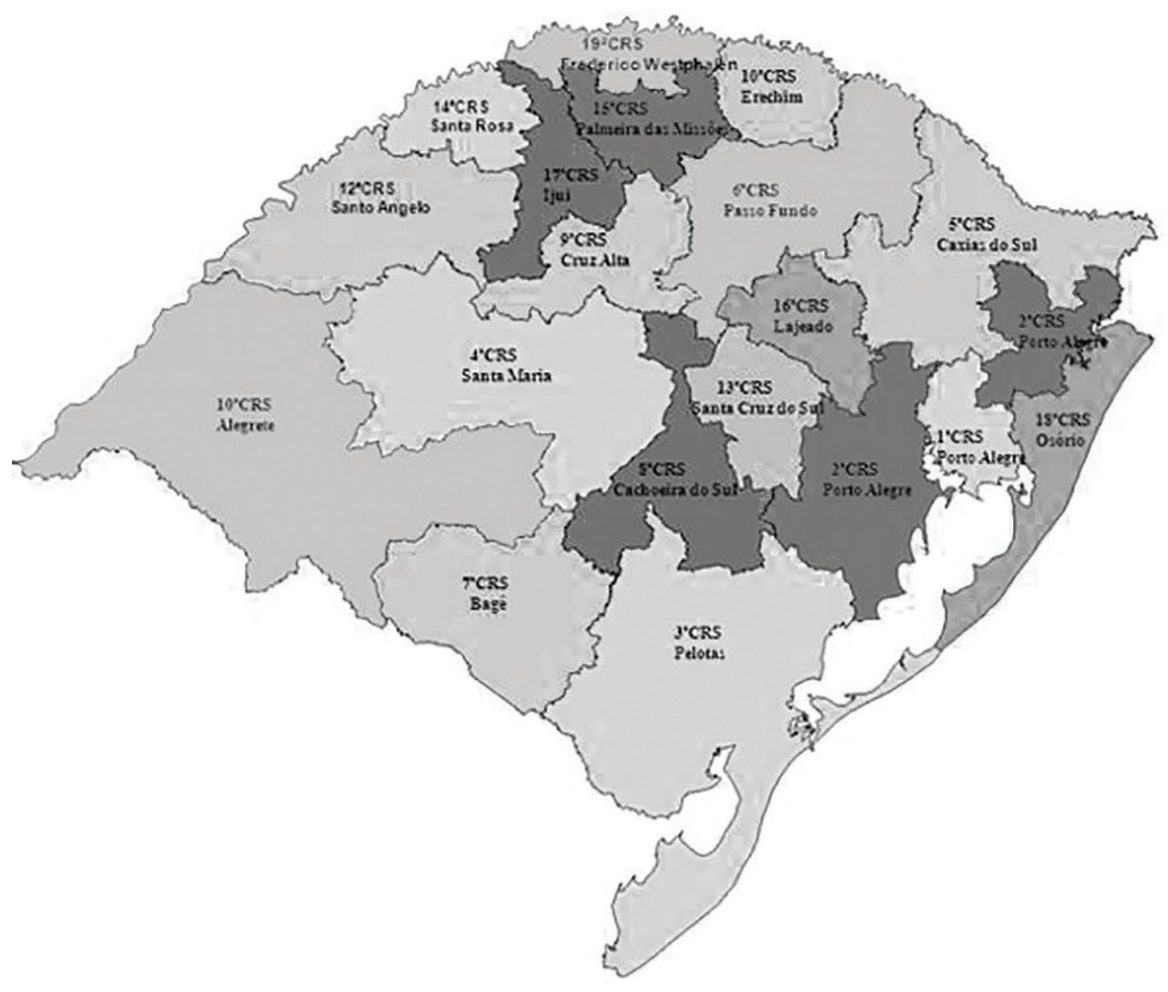

Figura 1 - Mapa das Coordenadorias Regionais de Saúde da SES/RS

Com o intuito de descentralizar as ações de Ouvidoria do SUS e possibilitar ao cidadão o atendimento e acompanhamento da sua demanda no próprio território, a Ouvidoria buscou integrar à sua Rede pontos de interlocução nas Secretarias Municipais de Saúde e em instituições de saúde vinculadas ao SUS. O organograma da Ouvidoria do SUS é muito similar ao de todas as outras redes do SUS, tendo representação nas três esferas de governo com a presença da regionalização - Coordenadorias Regionais de Saúde. Sinteticamente temos instituições públicas, privadas ou mistas, prestadoras de serviços SUS, Secretarias Municipais de Saúde, Coordenadorias Regionais de Saúde, Secretaria Estadual de Saúde e em seu último nível o Ministério da Saúde - todos integrados pelo Sistema Informatizado OuvidorSUS, o qual permite o fluxo de encaminhamentos e reencaminhamentos de protocolos, com novas informações, andamento, apurações etc., para as diferentes esferas. Todos estes entes têm acesso ao Sistema OuvidorSUS ou interlocução com o mesmo.

As Ouvidorias do SUS, independentemente da esfera em que estejam localizadas, têm como objetivo ser um canal de atendimento ao cidadão para recebimento de elogios, sugestões, solicitações, reclamações, denúncias e informações, sendo um dos espaços para o exercício da cidadania, participação e controle social. Têm a finalidade garantir a avaliação dos serviços de saúde, identificar áreas deficitárias, subsidiando a tomada de decisão dos gestores para melhoria da qualidade dos serviços de saúde. Ainda, exercem importante influência na educação permanente dos profissionais da saúde, os quais, através das demandas recebidas dos usuários, podem repensar seus processos de trabalho e qualificar o atendimento ao cidadão. Com a utilização do sistema 
informatizado (OuvidorSUS), é possível ter acesso a relatórios gerenciais, com tabulação de dados e identificação de temas recorrentes, disponíveis para acompanhamento nos planos estadual e federal, todos conectados ao mesmo sistema.

A fim de ampliar a participação de cidadãos do Estado, produzir relatórios para subsidiar a gestão do SUS, disseminar as informações quantificadas da Ouvidoria aos diversos atores da rede SUS, gerar mudanças nas práticas de cuidado e vigilância, aproximando-as com os anseios da população, fez-se necessário ampliar e qualificar a rede de Ouvidorias do SUS do Estado do Rio Grande do Sul, facilitando o acesso do cidadão, bem como dar celeridade ao tratamento das demandas.

\subsection{Procedimentos Metodológicos}

O objetivo desta pesquisa foi conhecer e identificar os assuntos mais recorrentes nos protocolos gerados na Ouvidoria do SUS do Rio Grande do Sul (RS), incluindo protocolos registrados na Ouvidoria Estadual e nas Ouvidorias Regionais do SUS. Trata-se de uma pesquisa de abordagem quantitativa realizada a partir dos dados disponíveis no sistema informatizado OuvidorSUS - Banco de Dados do Sistema OuvidorSUS, gerado na data de 06/01/2017 pelo Ministério da Saúde, contendo dados desde o início da Ouvidoria do SUS-RS com a utilização do Sistema OuvidorSUS - janeiro 2012 a dezembro de 2016 -, por meio da análise e categorização dos assuntos mais recorrentes nas manifestações de todas as demandas registradas durante esse período.

O Sistema OuvidorSUS, utilizado em todo território nacional, é um sistema informatizado que possibilita o registro das manifestações, sua categorização e gerenciamento dos dados gerados. Quanto ao meio de atendimento, a Ouvidoria do SUS-SES/RS recebe demandas via: cartas/documentos, formulário web, pessoalmente, telefone e e-mail. Quanto à classificação, concerne a: reclamações, denúncias, sugestões, elogios, solicitações e informações, de acordo com Portaria $\mathrm{n}^{\circ}$ 8, de 25 de maio de 2007 (BRASIL, 2007). No que compete à sua categorização, segundo o teor da manifestação do cidadão e às áreas de competência, as demandas são tipificadas de acordo com o Manual de Tipificação do Sistema Informatizado OuvidorSUS, elaborado pelo Departamento de Ouvidoria-Geral do SUS (DOGES/MS). O registro da manifestação é feito pelo atendente da Ouvidoria, por meio da abertura de um protocolo, o qual é classificado e tipificado. Os atendentes recebem capacitação para a tipificação correta dos protocolos e têm acesso ao Manual sempre que necessário. O Sistema permite até 04 (quatro) níveis de tipificação: Assunto; Subassunto 1; Subassunto 2; e Subassunto 3. Dentre os Assuntos (nível 1), temos: I. Alimento; II. Assistência à Saúde; III. Assistência Farmacêutica; IV. Assistência Odontológica; V. Assuntos Não Pertinentes; VI. Cartão SUS; VII. Comunicação; VIII. Conselho de Saúde; IX. Estratégia de Saúde da Família/Programa de Agentes Comunitários de Saúde (ESF/Pacs); X. Financeiro; XI. Gestão; XII. Orientações em Saúde; XIII.Ouvidoria do SUS; XIV. Produtos para Saúde/Correlatos; XV. Programa Farmácia Popular do Brasil; XVI. Programa Farmácia Popular do Brasil - Sistema Copagamento; XVII. Programa Nacional de Controle do Tabagismo (PNCT); XVIII. Programa Nacional de DST e AIDS; XIX. SAMU; XX. Transporte; XXI.Vigilância em Saúde; XXII.Vigilância Sanitária. A totalidade de subassuntos não está descrita neste trabalho pois compõe uma lista extensa de possibilidade de categorização. $O$

156 | Revista Científica da Associação Brasileira de Ouvidores/Ombudsman - Ano 1 - no 1 - 2017/2018 
referido Manual de Tipificação do Sistema contempla orientações a respeito dessa análise podendo ser utilizado por todas as Ouvidorias do SUS em seu processo de trabalho. A correta tipificação da demanda é fundamental para a qualidade do registro. Essa informação é importante para o encaminhamento adequado e para o tratamento da demanda; assim como para a elaboração de relatórios gerenciais fidedignos, utilizados como instrumento de gestão da Ouvidoria do SUS (BRASIL, 2014).

\subsection{Resultados}

Desde a criação da Ouvidoria até o final do ano de 2016, foram cadastradas 22.893 manifestações: 1.705 demandas em 2012, 3.431 em 2013, 4.730 em 2014, 6.931 em 2015 e 6.096 no ano de 2016 - Gráfico 1.

\section{GRÁFICO 1 - Total de Manifestações Registradas na Ouvidoria SUS da SES/RS por ano}

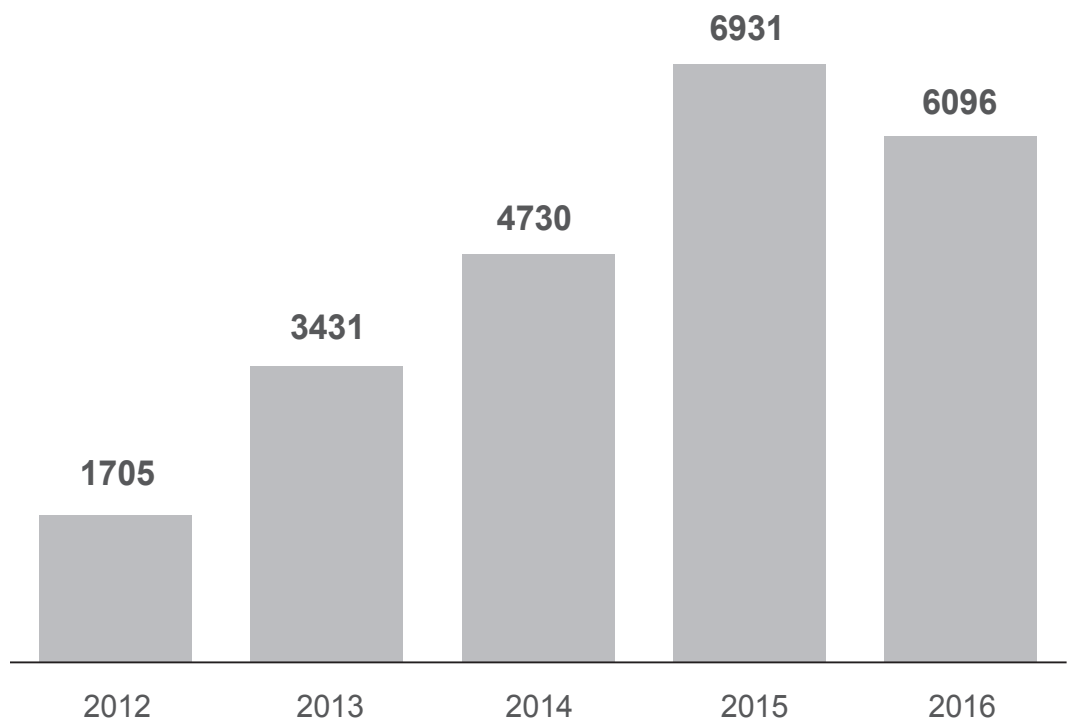

Fonte: Banco de Dados Sistema OuvidorSUS, gerado em 06 de janeiro de 2017

Nos primeiros anos da Ouvidoria, o principal canal de acesso utilizado foi o formulário web, alcançando $67 \%$ das manifestações. Porém, à medida que ocorreu a estruturação da Ouvidoria com equipe de Teleatendimento, o telefone passou a ser o principal meio de acesso utilizado, atingindo $80 \%$ dos atendimentos.

Dentre as 6.096 manifestações registradas em 2016, 79,2\% (4.831) foram por telefone; $11,3 \%$ (686) por formulário web; 4,8\% (294) por e-mail; 4,5\% (273) presencialmente; 0,1\% (7) carta e 0,1\% (5) correspondência oficial - Gráfico 2. 


\section{GRÁFICO 2 - Meio de Atendimento na Ouvidoria SUS da SES/RS em 2016}
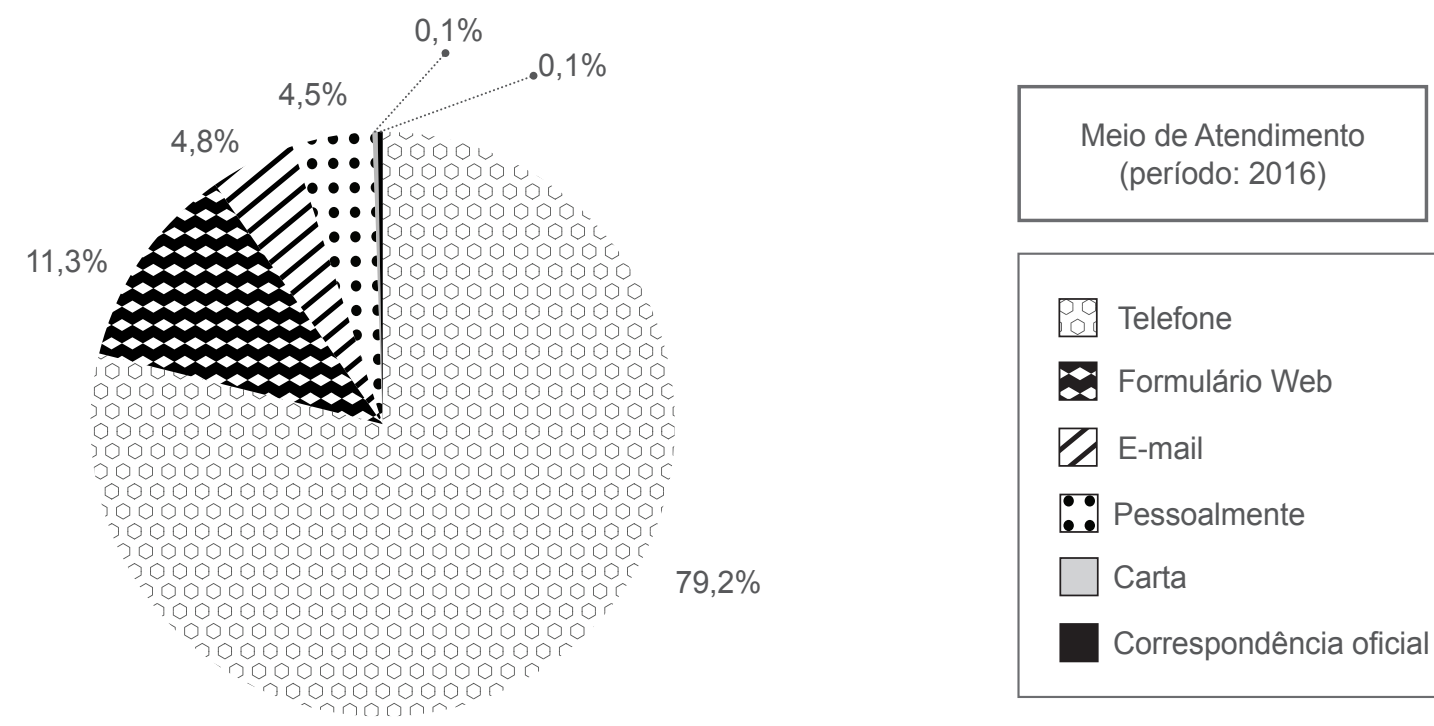

Telefone
Formulário Web
$\square$ Carta
Correspondência oficial

Fonte: Banco de Dados Sistema OuvidorSUS, gerado em 06 de janeiro de 2017

As manifestações da Ouvidoria são classificadas conforme o teor relatado pelo cidadão, tendo sido, em 2016, distribuídas em 64,06\% (3.905) Solicitações; 22,60\% (1.378) Reclamações; 7,40\% (451) Denúncias; 4,89\% (298) Informações; 0,56\% (34) Elogios; e 0,49\% (30) Sugestões Gráfico 3.

\section{GRÁFICO 3 - Classificação de Atendimento na Ouvidoria SUS da SES/RS em 2016}

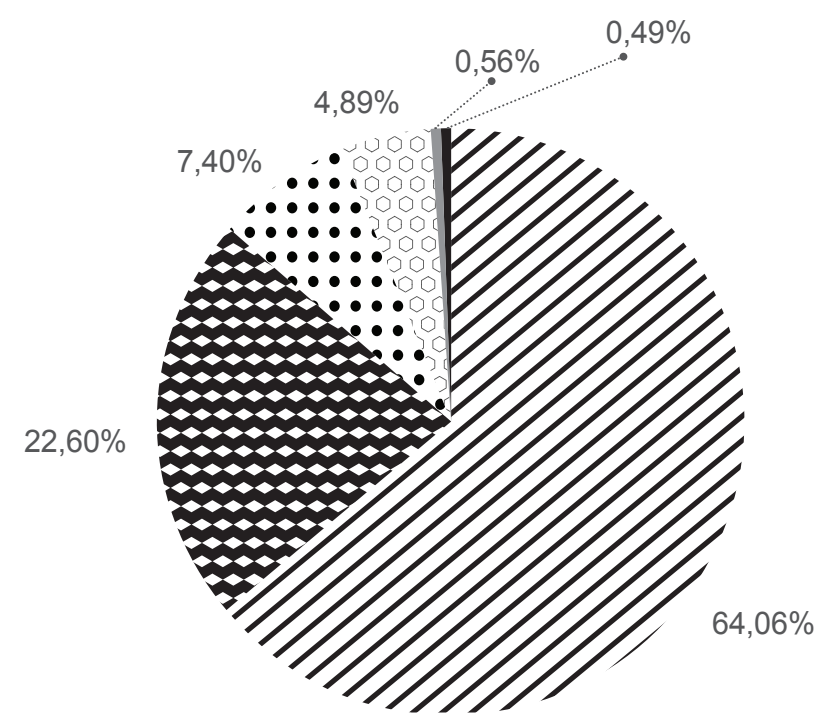

Por Classificação (período: 2016)

\begin{tabular}{|ll}
\hline Solicitação \\
Reclamação \\
$\square$ Informação \\
$\square$ Elogio \\
Sugestão
\end{tabular}

Fonte: Banco de Dados Sistema Ouvidor SUS, gerado em 06 de janeiro de 2017 
Em relação aos Assuntos mais recorrentes tivemos: 52,3\% (3.189 protocolos) relacionados à Assistência Farmacêutica; 14,1\% (860 protocolos) à Assistência à Saúde; 12,6\% (766 protocolos) à Gestão; 9,3\% (569 protocolos) a Alimentos; 2,3\% (141 protocolos) à Vigilância em Saúde; 2,1\% (127) à Vigilância Sanitária; e 7,3\% (444 protocolos) distribuídos em demais assuntos (Outros) Gráfico 4.

\section{GRÁFICO 4 - Classificação Quanto ao Assunto da Demanda - Ouvidoria SUS da SES/RS em 2016}

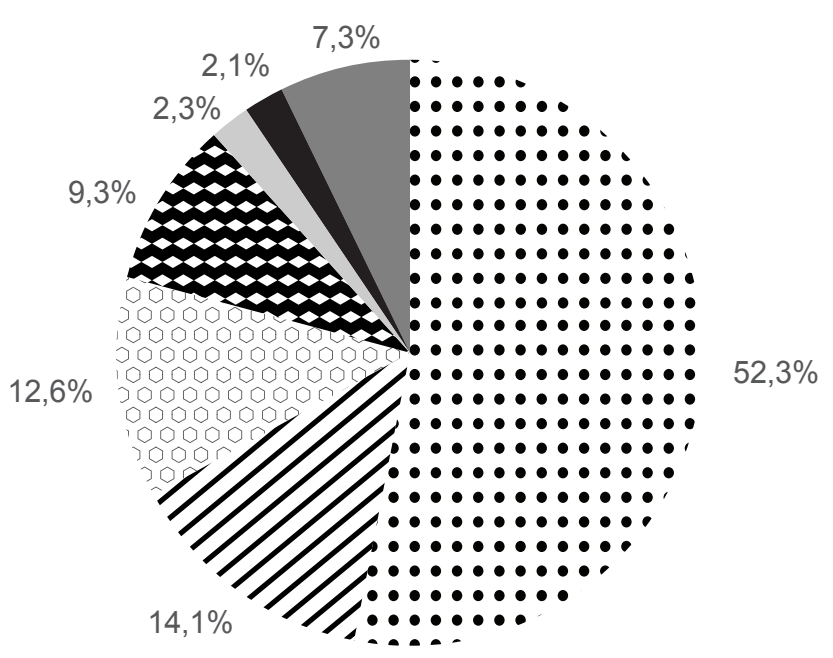

Por Assunto (período: 2016)

Assistência farmacêutica

Assistência à saúde

Gestão

Alimento

Vigilância em saúde

Vigilância sanitária

Outros

Fonte: Banco de Dados Sistema OuvidorSUS, gerado em 06 de janeiro de 2017

Das demandas da Assistência Farmacêutica - assunto mais recorrente -, 73\% (2.330 protocolos) foram sobre medicamentos do Componente Especializado, ou seja, medicamentos cuja compra é responsabilidade Federal e/ou Estadual; 11\% (346) Não Padronizado (medicamentos não fornecidos pelo SUS); 13\% (416) Outros; e 3\% (97) Medicamentos do Componente da Atenção Básica, responsabilidade Municipal.

Em Assistência à Saúde, $51 \%$ das manifestações foram sobre atendimento (consultas) e 29\% cirurgias, destacando-se as especialidades de Ortopedia/Traumatologia e Oftalmologia em ambos; e $20 \%$ outras solicitações. Em Gestão, predominaram reclamações e denúncias principalmente relacionadas a Recursos Humanos. As demandas foram encaminhadas a seus respectivos setores e órgãos do SUS prioritariamente pelo sistema OuvidorSUS, tanto os de gestão estadual, regional, municipal ou institucional.

Dentre as 6.096 manifestações registradas, 231 tiveram origem nas Ouvidorias Regionais do SUS, conforme distribuído nas respectivas CRS, no gráfico a seguir. No período analisado, 07 (sete) Ouvidorias Regionais não registraram nenhuma manifestação. 


\section{GRÁFICO 5 - Porcentagem de Registro nas Respectivas Coordenadorias Regionais de Saúde (CRS) da SES/RS em 2016}

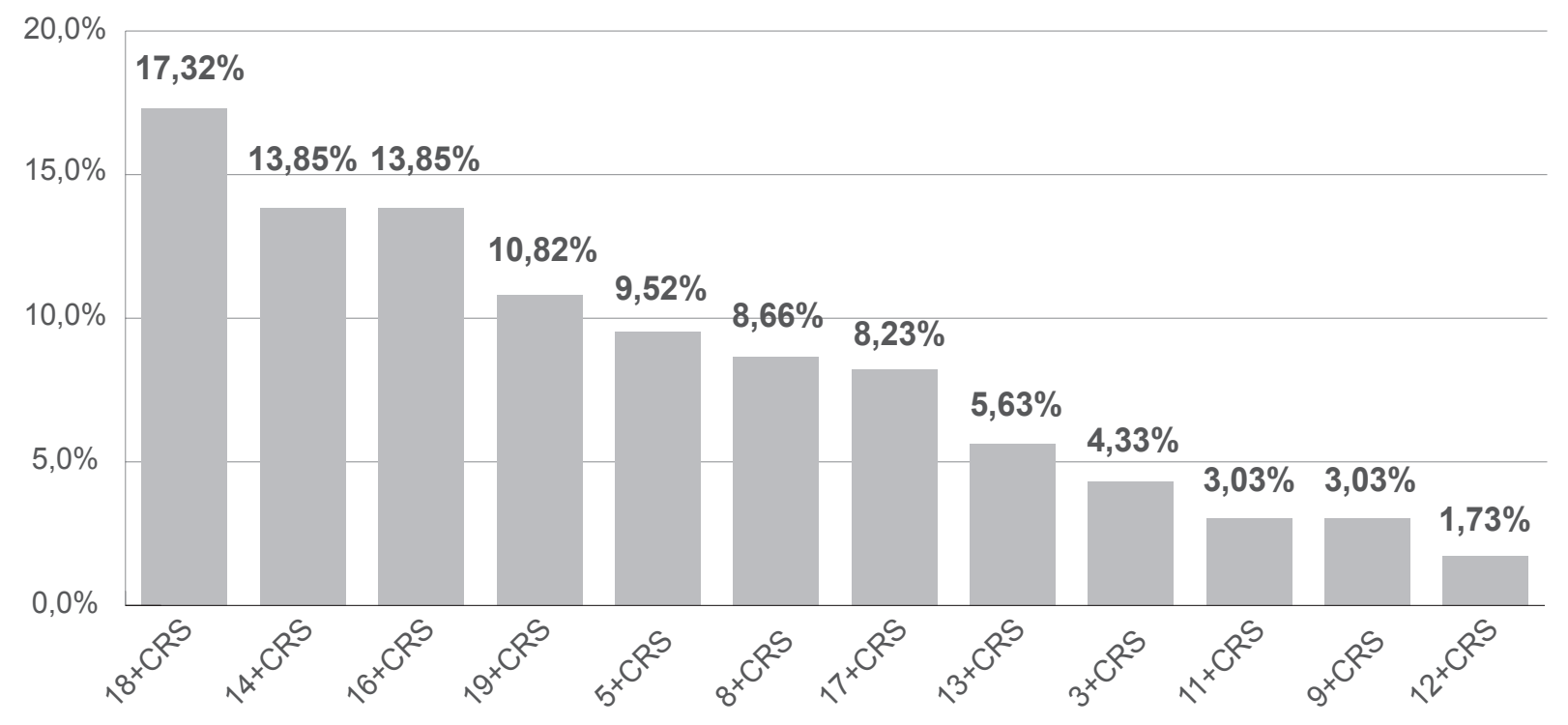

Fonte: Banco de Dados Sistema OuvidorSUS, gerado em 06 de janeiro de 2017

\subsection{Discussão}

O registro das manifestações no Sistema Informatizado OuvidorSUS permite que as manifestações tenham uma resolução ágil. A gestão da informação a partir da análise das demandas possibilita a visualização das principais áreas problemáticas com maior número de reclamações ou solicitações.

Em relação ao meio de atendimento, verifica-se que o canal de acesso mais utilizado pela população foi o telefone, o que pode ser explicado pelo fato de ser um canal telefônico 0800 gratuito, ou seja, sem custo ao cidadão. A equipe para o atendimento telefônico foi ampliada, dobrando o número de pontos de atendimento e disponibilizando maior acesso ao cidadão. O aumento da divulgação da Ouvidoria também culminou com o período de crescimento no número de registro de protocolos.

Considerando que a Ouvidoria não é o canal adequado para o atendimento de saúde, e sim os serviços de saúde, cabe ressaltar que as demandas classificadas como "Solicitação" expressam a dificuldade de acesso do cidadão a algum serviço de saúde. As solicitações e reclamações indicam a insatisfação do usuário do SUS, porém as solicitações permitem visualizar de imediato a insatisfação vinculada à necessidade de acesso. Em um número menor de registros estão as "Informações", porém a Ouvidoria dissemina muitas informações sem gerar protocolos, gerando apenas atendimentos, que não foram analisados neste estudo. Ainda é importante destacar que, em cada protocolo registrado, há alguma orientação ou informação fornecida, acenando para a subnotificação de "informações" nos registros da Ouvidoria. 
A análise da tipificação evidencia a "Assistência Farmacêutica" em seu "Componente Especializado", associada ao fato de as dificuldades encontradas pelo cidadão neste assunto serem de competência da SES, o que não nos permite inferir que este seja o principal problema da população do RS. Em contraponto, a análise destas manifestações pela Ouvidoria e Coordenação Estadual da Política de Assistência Farmacêutica tem gerado mudanças em fluxos de trabalho da farmácia do Estado.

O assunto "Assistência à Saúde" aponta as solicitações de usuários para atendimentos, ou seja, a dificuldade de acesso a consultas especializadas, cirurgias e exames. Muitas dessas demandas são de competência municipal, ressaltando aqui a necessidade do trabalho em rede na Ouvidoria do SUS. É importante destacar que nem sempre a dificuldade encontrada aqui está relacionada à "fila de espera", e sim à falta de informação nos sistemas de agendamento, possibilitando a atuação eficaz da Ouvidoria na resolução do problema.

Em gestão, terceiro item de maior recorrência, ressalta-se a insatisfação com recursos humanos, o qual incluiu críticas a atendimentos recebidos pelos profissionais de saúde ou de instituições prestadoras de serviço SUS. A partir da identificação e análise dos dados obtidos é possível influenciar no estabelecimento de metas e pactuações, para que as ações de planejamento reflitam efetiva e concretamente os anseios dos usuários.

Salientamos ainda que o sistema informatizado OuvidorSUS permite que uma mesma demanda seja encaminhada e analisada por diferentes setores, chegando ao seu destino final - local da reclamação ou solicitação - com maior rapidez.

A caracterização das demandas através de relatórios periódicos permite a utilização desses dados pelos gestores estaduais, regionais e municipais para a tomada de decisões, assim como sua utilização no planejamento em saúde. Nesse sentido, a Ouvidoria passou a integrar os instrumentos de gestão e planejamento em saúde da SES, como o RDQA - Relatório Detalhado do Quadrimestre Anterior, e o RAG - Relatório Anual de Gestão, inserindo, em formato de anexo aos documentos, um relatório simplificado das manifestações recebidas na Ouvidoria. Considerando que os relatórios são analisados pelo Controle Social por meio do Conselho Estadual de Saúde, a Ouvidoria contribui na efetivação da participação do cidadão na Gestão do SUS. Também passaram a integrar os instrumentos de planejamento: PES - Plano Estadual de Saúde, PAS - Programação Anual de Saúde, PPA - Plano Plurianual, LOA - Lei Orçamentária Anual, onde são pactuadas as diretrizes, objetivos, metas e ações para a saúde no período de 04 (quatro) anos, bem como são fixados os recursos financeiros para o atingimento das metas. Por meio da participação no grupo condutor de elaboração desses instrumentos, o GT PMeA - Grupo de Trabalho de Planejamento, Monitoramento e Avaliação, a Ouvidoria pode aproximar continuamente o olhar do cidadão às discussões de várias áreas técnicas desta Secretaria, contribuindo como ferramenta de gestão.

\section{CONSIDERAÇÕES}

Os dados obtidos na pesquisa refletem as demandas registradas na Ouvidoria do SUS do Estado do Rio Grande do Sul/RS, demonstrando as principais frustrações e dificuldades dos usuários. 
Entende-se que esta pesquisa deva ser utilizada para a avaliação e o planejamento das ações em saúde, assim como as estratégias utilizadas podem ser replicadas a fim de influenciar, inclusive, na elaboração do Plano Estadual de Saúde e na pactuação de indicadores e metas com os municípios.

É importante que os usuários, profissionais de saúde, gestores e prestadores de serviços se sintam acolhidos e ouvidos pela Ouvidoria, bem como que as demandas possam influenciar em ações estratégicas, sejam elas preventivas ou corretivas. Ademais, a análise de demandas e a sua discussão pela equipe envolvida podem despertar ações de educação permanente em saúde, influenciar na qualidade do atendimento ofertado ao usuário, bem como empoderar o cidadão para o exercício da cidadania e do controle social.

A Ouvidoria do SUS se mostrou um relevante dispositivo para planejamento em saúde, uma vez que dissemina informações a partir dos ouvidores SUS para todos os integrantes da rede, coordenadorias regionais, trabalhadores da gestão e da assistência, empoderando assim usuários e trabaIhadores de saúde. Ações desarticuladas de Ouvidoria, sem a intersecção com o controle social e os gestores, não propiciam mudanças nas práticas de saúde. A utilização de dados da Ouvidoria em Conselhos de Saúde e CIR, Comissão Intergestores Regional, é necessária para maiores resultados e efetivação da Ouvidoria como ferramenta de gestão. Ações no território, como as Ouvidorias Itinerantes, podem proporcionar maior aproximação com os cidadãos, bem como discussões acerca da cidadania e do SUS.

A Ouvidoria do SUS se apresentou como método para identificação de frentes de maior impacto no conjunto de debates que têm como fim o planejamento em saúde pública. O envio de relatórios periódicos aos gestores do SUS elucidou as principais demandas, influenciando tomadas de decisões. Oportunizaram-se comparações locorregionais em debates, como em reuniões de CIR, o que gera mudanças nas práticas das SMS. Foram realizados ainda eventos regionais a fim de informar os cidadãos sobre o trabalho da Ouvidoria do SUS, a rede de serviços do SUS, a importância do controle social e da participação nos Conselhos de Saúde. A Ouvidoria do SUS passou a compor o grupo de discussões para implementação do "Portal Cidadão", canal virtual destinado a resolver dúvidas.

Verifica-se que ainda há um árduo caminho a ser percorrido para a melhor utilização desta ferramenta de gestão do SUS. Ao passo que a Ouvidoria vem sendo reconhecida pelo cidadão como um espaço de escuta e acolhimento de suas necessidades, também cresce o desafio de abrir espaços na gestão para as ações da Ouvidoria. É cristalino que o proficiente alcance da Ouvidoria ainda envolve muitos desafios, como o relativo às demandas chegarem ao conhecimento dos diferentes atores que fazem parte da rede SUS, os quais talvez não estejam ao alcance dessas informações. Para contribuir com a melhoria dos serviços, a Ouvidoria do SUS deve interagir com os diferentes atores sociais envolvidos. Assim, permitir-se-á a ampliação da autonomia do próprio usuário, revelando sua participação como cidadão, o que fará com que este se torne protagonista do seu cuidado.

\section{REFERÊNCIAS}

BRASIL. MINISTÉRIO DA SAÚDE. Secretaria de Gestão Estratégica e Participativa. Departamento de Ouvidoria-Geral do SUS. Manual das Ouvidorias do SUS. Brasília: Ministério da Saúde, 2014b. Disponível em: <http://bvsms.saude. gov.br/bvs/publicacoes/manual_Ouvidoria_sus.pdf>. 
Lei $n^{\circ}$ 8.490, de 19 de novembro de 1992. Dispõe sobre a organização da Presidência da República e dos Ministérios e dá outras providências. Diário Oficial da União, Brasília, 19 nov. 92 (Ed. Extra).

Decreto $n^{\circ} 4.726$, de 9 de junho de 2003. Aprova a estrutura regimental e quadro demonstrativo dos cargos em comissão e das funções gratificadas do Ministério da Saúde e dá outras providências. Diário Oficial da União. 10 jun. 2003.

Lei Orgânica de Saúde n. 8.080, de 19 de setembro de 1990. Dispõe sobre as condições para a promoção, proteção e recuperação de saúde, a organização e o funcionamento dos serviços correspondentes e dá outras providências. Diário Oficial da União, Brasília, 20 set. 1990.

Lei n. ${ }^{\circ} 8.142$, de 28 de dezembro de 1990. Dispõe sobre a participação da comunidade na gestão do Sistema Único de Saúde - SUS e sobre as transferências intergovernamentais de recursos financeiros na área da saúde e dá outras providências. Brasília: Ministério da Saúde, 1990.

MINISTÉRIO DA SAÚDE. Sistema Único de Saúde (SUS): Entendendo o SUS. Brasília: BRASIL, MINISTÉRIO da Saúde, 2006. Disponível em: http://portalarquivos.saude.gov.br/images/pdf/2013/agosto/28/cartilha-entendendo-o-sus-2007.pdf Acesso em: 21 dez. 2011.

Decreto $n^{\circ} 7.508,28$ de junho de 2011. Regulamenta a Lei $n^{\circ} 8.080$, de 19 de setembro de 1990, para dispor sobre a organização do Sistema Único de Saúde - SUS, o planejamento da saúde, a assistência à saúde e a articulação interfederativa e dá outras providências. Diário Oficial da União, Brasília, 29 jun. 2011.

MINISTÉRIO DA SAÚDE (MS). Secretaria de Gestão Estratégica e Participativa. Portaria Nº 8, de 25 de maio de 2007. Regulamenta o Sistema OuvidorSUS. Diário Oficial da União, Brasília, 26 maio 2007.

CESARO, B. C.; GEHRES L. G. Banco de Dados do Sistema OuvidorSUS gerado em 06 jan. 2017 [on-line]. Disponível em: Ouvidoria-sus@saude.rs.gov.br. Acesso em: jan. 2017.

LYRA, Rubens Pinto. Autônomas x Obedientes. A Ouvidoria Pública em Debate. João Pessoa: UFPB. 2004.172 p.

OMBUDSMAN SASKATCHEWAN. The history of the Ombudsman. Regina. 2008. Disponível em: <http://www.ombudsman.sk.ca/info/the-history-of-the-ombudsman>. Acesso em: 9 jun. 2015.

PEIXOTO, Stefano Frugoli; MARSIGLIA, Regina Maria Giffoni; MORRONE, Luiz Carlos. Atribuições de uma Ouvidoria: opinião de usuários e funcionários. Saúde soc. São Paulo, v. 22, n. 3, p. 785-794, set. 2013. Disponível em: $<$ http://www.scielo.br/scielo.php?script=sci_arttext\&pid=S0104-12902013000300012\&lng=en\&nrm=iso>. Acesso em: 9 jun. 2015.

PINTO, E.; LYRA, R. P. Modalidades de Ouvidoria Pública no Brasil. João Pessoa: UFPB. 2009.

RIO GRANDE DO SUL. Decreto n. ${ }^{\circ} 51.999$, de 13 de novembro de 2014.

ZAVERUCHA, Jorge. O papel da Ouvidoria de polícia. Sociologias, Porto Alegre, n. 20, p. 224-235,. dec. 2008. Disponível em: <http://www.scielo.br/scielo.php?script=sci_arttext\&pid=S1517-45222008000200010\&lng=en\&nrm=iso>. Acesso em: 24 jan. 2016.

\section{ANEXO}

\section{Siglas e Legendas}

CIR - Comissão Intergestores Regional

CRS - Coordenadorias Regionais de Saúde

DOGES - Departamento de Ouvidoria-Geral do SUS

GT PMeA - Grupo de Trabalho de Planejamento,

Monitoramento e Avaliação

LOA - Lei Orçamentária Anual

MS - Ministério da Saúde
PAS - Programação Anual de Saúde

PES - Plano Estadual de Saúde

PPA - Plano Plurianual

RAG - Relatório Anual de Saúde

RDQA - Relatório Detalhado do Quadrimestre

Anterior

RS - Rio Grande do Sul

SES - Secretaria Estadual da Saúde

SMS - Secretarias Municipais de Saúde

SUS - Sistema Único de Saúde 